\title{
Hypothalamic abnormalities and Parkinsonism associated with H1N1 influenza infection
}

\author{
Alejandra González-Duarte*, Lucía Magaña Zamora, Carlos Cantú Brito, Guillermo García-Ramos
}

\begin{abstract}
Objective: To describe a case of a young adult with severe H1N1 influenza illness associated with hypothalamic abnormalities and post-influenza parkinsonism.

Design: Case report.

Patient: A 22-year-old woman with H1N1 influenza infection developed encephalopathy followed by diverse hypothalamic dysfunction manifestations, sleeplessness, and persistent parkinsonian features.

Results: CSF analysis, brain imaging and EEG ruled out hypoxic brain injury or other illnesses.

Conclusions: A number of viruses have been associated with both acute and chronic parkinsonism. A link between parkinsonism and influenza viruses is somewhat controversial. This is the first reported case of parkinsonism following an H1N1 influenza infection.
\end{abstract}

\section{Background}

The full incidence of neurologic complications and sequelae from the 2009 influenza A (H1N1) pandemic has yet to be determined. There is a large body of evidence that influenza can directly lead to encephalitis; however, a link with Parkinson's disease is somewhat controversial [1]. Many of the influenza viruses have not demonstrated clear neurotropism, and they rarely produce a true neuroinvasive disease. For this reason, a possible connection between postencephalic Parkinson's disease and influenza is based only on simultaneous occurrence. The recognition of neurologic post-influenzal disease has been based on coincidental occurrence with influenza pandemics, and to date there are no diagnostic serological, animal or electrographical confirmation tests. In 1974, Gamboa et al [2] found antigen material related to neurotropic influenza strain A0 in some neurons of the hypothalamus and substantia nigra in postencephalitic parkinsonian brains. Other reports have also found Influenza viral RNA in cerebrospinal fluid $[3,4]$. However, these findings have not been consistent. Moreover, the failure to demonstrate differences in influenza virus $\mathrm{H} 1$ antibodies between postencephalic

\footnotetext{
* Correspondence: gonzalezduarte@aol.com

Department of Neurology, Instituto Nacional de Ciencias Médicas y Nutrición Salvador Zubirán, México D.F., México
}

(c) 2010 González-Duarte et al; licensee BioMed Central Ltd. This is an Open Access article distributed under the terms of the Creative Commons Attribution License (http://creativecommons.org/licenses/by/2.0), which permits unrestricted use, distribution, and reproduction in any medium, provided the original work is properly cited.

\section{Case summary}

A previously healthy 22-year-old Hispanic female was admitted to a local hospital after two weeks of fever of $39.5^{\circ} \mathrm{C}\left(103.1^{\circ} \mathrm{F}\right)$, non-productive cough, dyspnea and cyanosis. Community acquired pneumonia or influenza H1N1 was suspected, and treatment with clarithromycin, ceftriaxone and oseltamivir was initiated. She required intubation and mechanical ventilation, and was referred to our institution.

Upon her arrival, she was moderately agitated despite sedation. Her blood pressure was $130 / 90 \mathrm{mmHg}$, with a heart rate of 100 beats per minute, a temperature of $37^{\circ} \mathrm{C}$ and an $\mathrm{O}_{2}$ saturation of $80 \%$. Her WBC was $13,500 \mathrm{cel} / \mathrm{mm}^{3}$, with $86 \%$ neutrophils and $7.9 \%$ 
lymphocytes; serum glucose was $129 \mathrm{mg} / \mathrm{dL}$, sodium $132 \mathrm{mEq} / \mathrm{L}$, and creatinine $0.49 \mathrm{mg} / \mathrm{dL}$. A thoracic CT scan showed bilateral infiltrates consistent with pneumonia. Ceftriaxone treatment was changed to piperazillin and tazobactam, while treatment with clarithromycin and oseltamivir was continued. She also received amantadine for 3 days, but this was discontinued after detection of H1N1 influenza RNA by RT-PCR (CDC Realtime $r T P C R$, dual-labeled hydrolyisis TaqMan ${ }^{\circ}$ probes, 2009 CDC protocol for detection and characterization of swine influenza) in a nasopharyngeal swab.

Over the following days, her sodium levels increased to $151 \mathrm{mEq} / \mathrm{L}$ despite treatment with free water. As the urine osmolality was persistently low, diabetes insipidus was suspected, and intranasal desmopressin was initiated. Twenty days later she was extubated. While fentanyl and midazolam were being titrated down, she became severely agitated and was treated with haloperidol. Around that time a generalized resting tremor was noted, predominately on the left leg and left arm, as well as masked face, decreased blinking, and cogwheel phenomena. She did not have elevated temperature or elevation of serum CPK levels. Haloperidol was discontinued, but the tremor did not subside. EEG and brain MRI were normal; specifically, there were no signs of pontine myelinolysis or basal ganglia abnormalities. CSF analysis was normal, with 0 cells/ $\mathrm{mm}^{3}$, protein $39 \mathrm{mg} / \mathrm{dL}$ and glucose $47 \mathrm{mg} / \mathrm{dL}$ (serum glucose $75 \mathrm{mg} / \mathrm{dL}$ ). Seven days later she developed severe autonomic cardiovascular fluctuations consistent with bouts of hypertension alternated with hypotension, brady and tachyarrhythmias. Her blood pressure ranged from $160 / 100 \mathrm{mmHg}$ to $80 / 40 \mathrm{mmHg}$ and her heart rate ranged from 180 beats per minute to 35 beats per minute (Figure 1). Soon after clonidine was started, her heart rate and blood pressure became stable.

Six months later she still complains of diurnal somnolence, insomnia and hyperhidrosis. She is alert and answers questions appropriately, although her behavior is disinhibited at times. Cranial nerve examination is normal. Muscle strength is 3/5 in upper and lower extremities, and there is muscle atrophy. Deep tendon reflexes are globally diminished. Plantar reflexes are flexor. She displays parkinsonian features despite the use of biperiden and clonazepam (Additional file 1).

\section{Discussion}

We describe psychomotor agitation at onset, several hypothalamic abnormalities, sleeplessness and changes in conduct occurring in an otherwise healthy young adult with $\mathrm{H} 1 \mathrm{~N} 1$ influenza infection. The findings of

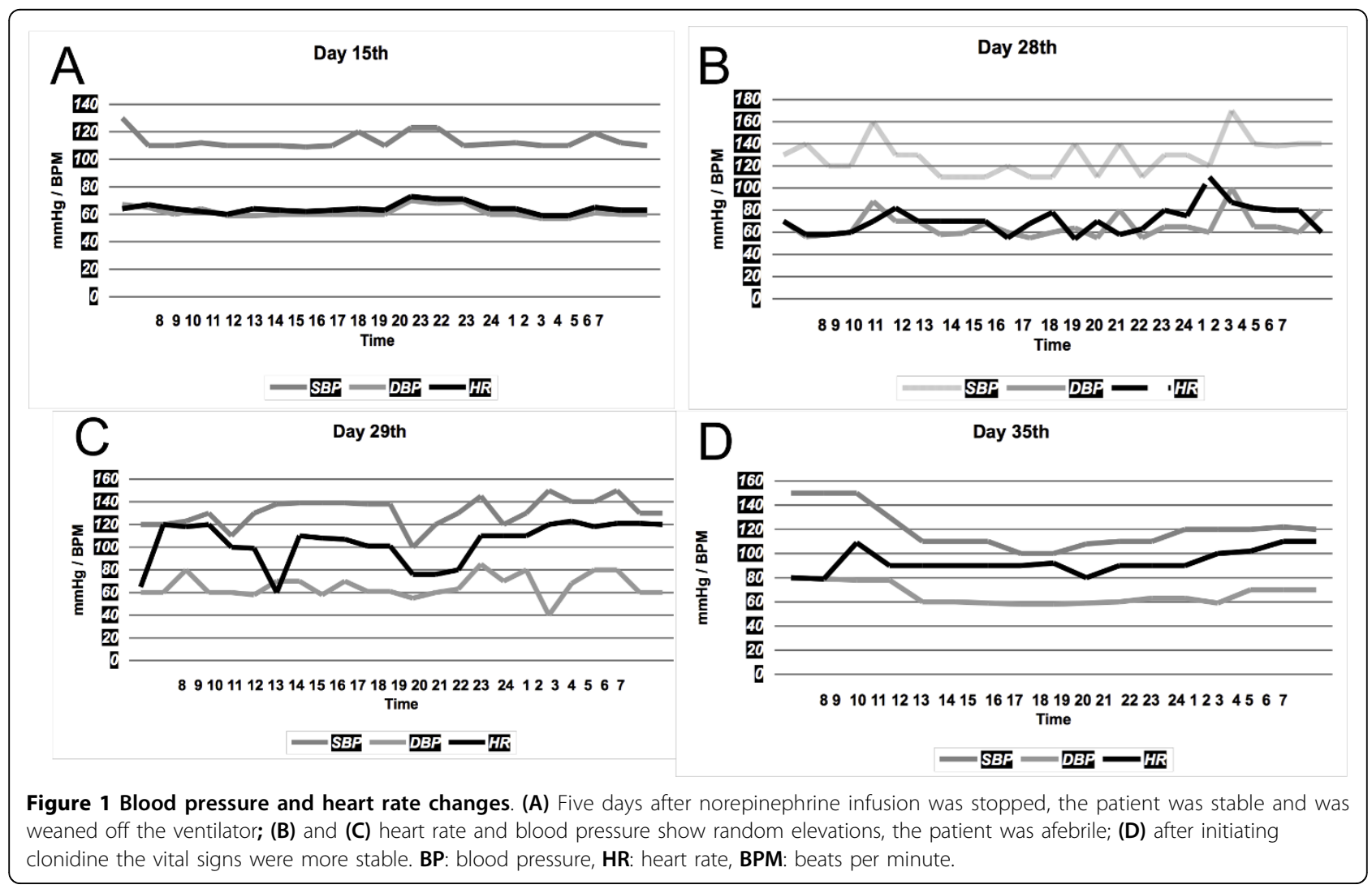


neurogenic deficiency of arginine-vasopressin (AVP), autonomic hyperactivity, loss of the circadian rhythm, behavioral inappropriateness, and hyperhidrosis support the involvement of the hypothalamus. The patient still displays post-encephalic parkinsonian motor symptoms consistent of bradykinesia, tremor and "mask like" face months after the acute illness.

Paroxysmal autonomic instability has been associated with encephalitis among other intracranial catastrophes. It consists of severe blood pressure fluctuations with wide pulse pressure, tachyarrhythmias, hyperthermia and hyperhidrosis [10] with or without dystonia [11]. This dramatic response reflects direct excitation, disinhibition, or both, of sympathoexcitatory areas of the hypothalamus or the medulla [10]. Neurogenic pulmonary edema, neurocardiogenic injury, cardiac arrhythmias, and sudden death are among the most dreaded possible complications [10]. Neuroleptic malignant syndrome (NMS) is a severe idiosyncratic reaction resulting from impaired central dopaminergic transmission in the hypothalamus and basal ganglia. Two common triggers are drug-induced blockade of D2-dopaminergic receptors and sudden withdrawal of dopaminergic agonists. While the use of haloperidol and amantadine withdrawal have been linked to NMS, the lack of full recovery and the absence of CPK elevations does not support NMS in our patient.

Neurologic complications of the influenza virus are uncommon complications of a very common infection. The pathogenesis is still not fully understood. The absence of a significant inflammatory response in the CSF supports para-infectious or post-infectious immune mechanisms. The hypothalamus coordinates many complex patterns of neuroendocrine outputs, circadian rhythms, homeostatic mechanisms and behavior. Although acute hypothalamic-pituitary-adrenal axis responses to stress are generally adaptive, excessive responses can lead to deleterious effects. Specialized brain regions that lack an effective blood-brain barrier include the hypothalamus and circumventricular areas. The capillary endothelium is fenestrated to allow free passage of large proteins and other molecules. These structures are densely vascularized and may be the site of action of interleukins to elicit both fever and ACTH secretion. Several studies have proposed a central role for various inflammatory cytokines in the genesis of influenza-associated neurologic illness [9]. Rather than a direct neuroinvasion, it is possible that the hypothalamus and surrounding structures are vulnerable to the massive cytokinemia produced in patients with more severe forms of influenza. However, it is also likely that a spectrum of illnesses or underlying factors is at play, and more research needs to be done.
Sporadic cases clinically diagnosed as H1N1-associated neurologic complications attract close attention, not just as a matter of historical curiosity, but as observational evidence to obtain objective data. The severity of neurologic sequelae warrant efforts to investigate these sporadic cases to better understand various chronic neurologic conditions, especially parkinsonism.

In summary, our patient displays several hypothalamic abnormalities and post-encephalic parkinsonian features. The exclusion of other possible etiologies of acute neurologic illness, combined with supportive evidence of acute influenza virus infection, suggests that these are influenza-associated complications. Case reports like ours highlight the threat of CNS involvement. Although rare, these neurologic manifestations may be overlooked in patients with $\mathrm{H} 1 \mathrm{~N} 1$ influenza.

\section{Additional material}

Additional File 1: Video 1 3GPP movie Video 1 showing persistent unilateral tremor. The patient displays an involuntary oscillating rhythmic tremor in her left arm that is present at rest, although it is better visualized for video purposes while she is stretching her arms. A masked face is also present. These features were not present before her hospital stay.

\section{Acknowledgements}

The authors would like to thank all the intensive care unit doctors for the care and support of the patient. This work was supported by the Consejo Nacional de Ciencia y Tecnologia (CONACYT) through the Fondo Sectorial de Investigación en Salud y Seguridad Social in aids to the H1N1 influenza pandemic research.

\section{Authors' contributions}

AGD participated in the evaluation and care of the patient, analyzed the data and wrote the manuscript. LMG participated in acquisition of data. All authors contributed in the evaluation and care of the patient and review of the manuscript. All authors read and approved the final manuscript.

\section{Competing interests}

The authors declare that they have no competing interests. Consent

Written informed consent was obtained from the patient for publication of this case report and accompanying images. A copy of the written consent is available for review by the Editor-in-Chief of this journal.

Received: 30 June 2010 Accepted: 17 August 2010

Published: 17 August 2010

\section{References}

1. Jang $H$, Boltz DA, Webster RG, Smeyne RJ: Viral parkinsonism. Biochim Biophys Acta 2009, 1792:714-721.

2. Gamboa ET, Wolf A, Yahr MD, Harter DH, Duffy PE, Barden H, Hsu KC: Influenza virus antigen in postencephalitic parkinsonism brain: Detection by immunofluorescence. Arch Neurol 1974, 31:228-232.

3. Rarttila R, Halonen P, Rinne Urpo: Influenza Virus antibodies in parkinsonism. Arch Neurol 1977, 34:99-100.

4. Fujimoto $S$, Kobayashi M, Uemura O, Iwasa M, Ando T, Katoh T, Nakamura C, Maki N, Togari H, Wada Y: PCR on cerebrospinal fluid to show influenza-associated acute encephalopathy or encephalitis. Lancet 1998, 352:873-875 
5. Fugate J, Lam Erek, Rabinstein AA, Wijdicks EF: Acute Hemorrhagic Leukoencephalitis and Hypoxic Brain Injury Associated with H1N1 Influenza. Arch Neurol 2010, 676:756-758.

6. Webster RI, Hazelton B, Suleiman J, Macartney K, Kesson A, Dale RC: Severe encephalopathy with swine origin influenza A H1N1 infection in childhood: Case reports. Neurology 2010, 74:1077-1078.

7. Centers for Disease Control and Prevention (CDC): Neurologic complications associated with novel influenza A (H1N1) virus infection in children - Dallas, Texas, May 2009. MMWR Morb Mortal Wkly Rep 2009, 58:773-778.

8. Baltagi SA, Shoykhet M, Felmet K, Kochanek PM, Bell MJ: Neurological sequelae of 2009 influenza A (H1N1) in children: A case series observed during a pandemic. Pediatr Crit Care Med 2010, 11:179-184.

9. Sejvar JJ, Uyeki TM: Neurologic complications of 2009 influenza A (H1N1): Heightened attention on an ongoing question. Neurology 2010, 74:1020-1021.

10. Blackman JA, Patrick PD, Buck ML, Rust RS Jr: Paroxysmal autonomic instability with dystonia after brain injury. Arch Neurol 2004, 61:321-328.

11. Rabinstein AA: Paroxysmal autonomic instability after brain injury. Arch Neurol 2004, 61:1625.

doi:10.1186/1742-2094-7-47

Cite this article as: González-Duarte et al:: Hypothalamic abnormalities and Parkinsonism associated with H1N1 influenza infection. Journal of Neuroinflammation 2010 7:47.

\section{Submit your next manuscript to BioMed Central and take full advantage of:}

- Convenient online submission

- Thorough peer review

- No space constraints or color figure charges

- Immediate publication on acceptance

- Inclusion in PubMed, CAS, Scopus and Google Scholar

- Research which is freely available for redistribution

Submit your manuscript at www.biomedcentral.com/submit 